\title{
Social Policy and Abortion: A Review of the Research
}

\author{
Marshall H. Medoff* \\ Department of Economics, California State University, Long Beach, 1250 Bellflower Boulevard, Long Beach, CA \\ 90840, USA
}

\begin{abstract}
Since the Supreme Court's 1973 decision legalizing abortion, many states have enacted laws restricting women's access to an abortion. There has been considerable empirical research on the impact of these restrictive state abortion laws on women's pregnancy resolution decisions. This paper reviews the empirical evidence regarding restrictions on abortion access. The empirical evidence indicates that demand-side policies (i.e., No Medicaid Funding, Parental Involvement Laws, Mandatory Counseling Laws, Mandatory Waiting Periods Laws, Partial-Birth Abortion Bans) have little effect on the incidence of abortion. TRAP laws, which are supply-side policies, have the greatest effect reducing abortion services.
\end{abstract}

Keywords: Abortion, restrictive state abortion laws, state abortion policies.

\section{INTRODUCTION}

The U.S. Supreme Court's 1973 Roe v. Wade decision legalizing abortion recognized that states have the right to regulate the procedure. During the first trimester of pregnancy, states could not enact any laws or regulations that restricted a woman's access to an abortion. During the second trimester, states could enact laws regulating abortion access, but only if the law had a compelling interest in protecting a pregnant woman's maternal health. During the third trimester, when the fetus is viable, states could enact laws restricting or even prohibiting abortions provided there was a medical exception to protect the life or health of the pregnant woman.

In 1992, the Supreme Court in Planned Parenthood of Southeastern Pennsylvania v. Casey rejected Roe's rigid trimester pregnancy framework of state abortion regulation and replaced it with the "undue burden" standard. The court ruled that states could impose restrictions on a woman's access to an abortion provided that the state law or regulation did not have ".. the purpose or effect of placing a substantial obstacle in the path of a woman seeking an abortion of a nonviable fetus". The ambiguity of the undue burden standard enabled many states to enact a variety of restrictive abortion laws.

Restrictive state abortion laws may influence the likelihood of women terminating an unwanted pregnancy in two ways. First, restrictive abortion laws may increase the financial costs (e.g., out-of-pocket cost of the abortion, expenses on travel and accommodations, lost work time, childcare expenses) and the emotional costs (e.g., guilt, remorse, regret, humiliation, psychological trauma) incurred by women

*Address correspondence to this author at the Department of Economics, California State University, Long Beach, 1250 Bellflower Boulevard, Long Beach, CA 90840, USA; Tel: 562-985-5077; Fax: 562-985-5804;

E-mail: Marshall.Medoff@csulb.edu seeking an abortion. Second, restrictive abortion laws may decrease the availability of abortion services by reducing the number of abortion providers resulting in an increase in both women's search costs in locating an abortion provider and the time costs associated with obtaining an abortion. The more restrictive the abortion law, the more costly the abortion. If abortions become more costly, women will have fewer of them.

The manner in which restrictive state abortion laws alter women's pregnancy resolution decision-making calculus can be objectively answered. The purpose of this paper is to examine the theoretical framework that provides specific behavioral predictions that would result from the enforcement of restrictive state abortion laws. The paper also reviews the empirical evidence estimating the impact of restrictive state abortion laws.

\section{THEORETICAL PERSPECTIVES}

The decision to have an abortion is embedded in the theoretical decision-making model of fertility control developed by Becker [1] and extended by Michael [2] and Willis [3]. Becker's fertility control model is predicated on the assumption that women make rational decisions about sexual activity, contraceptive use and pregnancy resolution based on a comparison of the respective costs and benefits of each alternative. The specific decisions that sexually active women have to make are whether to have an abortion or give birth if pregnant and how intensively to use contraception. Sexually active women compare the benefits and costs of an unwanted pregnancy/birth in making the decision to use contraception and which method to use. For women who want to have a child, a birth will provide a net benefit and an abortion is an irrelevant option for them. For other women the costs of an unwanted birth (e.g., lost earnings, education, labor market experience, marital prospects) exceed the benefits. These women will use contraception to reduce the likelihood of an unwanted pregnancy. Abortion is an ex post 
birth control method - an insurance policy that can be used when an unwanted pregnancy occurs - that reduces the likelihood of an unwanted pregnancy to zero.

More formally, the demand for abortion is assumed to be a function of the cost of an abortion and the number of unwanted pregnancies which, in turn, is assumed to be a function of the cost of an abortion and the effectiveness of other contraceptive methods.

$\mathrm{A}=\mathrm{f}(\mathrm{C}, \mathrm{P}(\mathrm{C}, \mathrm{Z}))$

Where $\mathrm{A}$ is the number of abortions, $\mathrm{C}$ is the cost of an abortion, $\mathrm{P}$ is the number of unwanted pregnancies and $\mathrm{Z}$ is a vector of alternative contraceptive methods. The cost of an abortion $\mathrm{C}$ may refer to the direct monetary costs (price of an abortion; travel expenses; lost earnings) or the indirect costs (emotional costs such as trauma, guilt, regret, shame; time costs; restrictive abortion laws.)

It is assumed that abortions follow the fundamental law of demand: an increase in the cost of obtaining an abortion causes a reduction in the number of abortions $(\partial \mathrm{A} / \partial \mathrm{C}<$ $0)$. Also, increases in the number of unwanted pregnancies will increase the number of abortions $(\partial \mathrm{A} / \partial \mathrm{P}>0)$ since some of the increases in the number of unwanted pregnancies will be terminated.

An increase in the cost of an abortion C, due to the imposition of a restrictive abortion law, from (1) is given by

$$
\frac{d A}{d C}=\frac{\partial A}{\partial C}+\frac{\partial A}{\partial P} \frac{\partial P}{\partial C}
$$

If women incorporate the increase in abortion costs $\mathrm{C}$, after an unwanted pregnancy occurs, then $\partial P / \partial C=0$ and the second term on the right-hand side of (2) is zero. The remaining first term $(\partial \mathrm{A} / \partial \mathrm{C})$ on the right-hand side of (2) is the reduction in the number of abortions of women with unwanted pregnancies as a consequence of the enforcement of a restrictive abortion law.

Kane and Staiger [4] argue that an unwanted pregnancy is not a predetermined event, but is an outcome based on prior decisions made by sexually active women regarding their use and choice of contraception. The Kane and Staiger model argues that restrictive abortion laws may affect the antecedents of an unwanted pregnancy - contraceptive use and methods. That is, the enforcement of a restrictive abortion law may alter sexually active women's prior decisions regarding their use and choice of a contraceptive method in order to reduce the likelihood of an unwanted pregnancy.

An increase in the cost of abortion, due to the enforcement of a restrictive abortion law, increases the cost of engaging in noncontracepted sexual activity relative to the cost of engaging in contracepted sexual activity and may induce sexually active women away from the abortion option and towards alternative birth control methods that reduce the likelihood of an unwanted pregnancy $(\partial P / \partial C<0)$. It follows from (2) that, if increases in abortion costs alter the likelihood of a pregnancy, an increase in the cost of an abortion C, due to the enforcement of a restrictive abortion law, will decrease the number of unwanted pregnancies and, concomitantly, the number of abortions of unwanted pregnancies.
Thus (2) yields two empirically verifiable theoretical predictions: (i) an increase in the cost of an abortion, due to the enforcement of a restrictive abortion law, will reduce the number of abortions of unwanted pregnancies per 1000 unwanted pregnancies; and (ii) if an increase in the cost of an abortion alters sexually active women's pregnancy avoidance behavior, then the enforcement of a restrictive abortion law will reduce the number of abortions of unwanted pregnancies per 1000 women of childbearing ages 15-44 years.

\section{ABORTION RATE AND ABORTION RATIO}

The ideal variable to examine the impact of various restrictive abortion laws is the incidence of unintended pregnancies that result in an abortion. No study has examined the effect restrictive abortion laws have on women's unintended pregnancy resolution decisions. The reason is that data on unintended pregnancies that result in an abortion are unavailable. Studies that use cross-section data (50 states for a specific year) or pooled cross-section time-series data (50 states over a number of years) to empirically estimate the impact of various restrictive state abortion laws on the incidence of abortion use two different abortion demand dependent variables. Some use the abortion ratio (the number of abortions per 1000 pregnancies) or the abortion rate (the number of abortions per 1000 women of childbearing age 15-44 years). Conceptually, these are two different dependent variables.

The abortion ratio measures the likelihood a pregnancy will result in an abortion (i.e., the abortion ratio considers only these women who are already pregnant). The abortion rate measures the likelihood that women of childbearing age become pregnant and have an abortion (i.e., the abortion rate considers all women of childbearing age: these who are not sexually active and those who are sexually active and practice safe or unsafe sex). The abortion rate is the product of the number of women of childbearing age who become pregnant and the likelihood that those pregnancies result in an abortion (i.e., abortion rate $=$ number of pregnancies $\times$ abortion ratio). An increase in the direct or indirect cost of an abortion is predicted to have an unambiguously negative effect on the likelihood of a pregnancy being terminated ( $\partial$ Abortion Ratio/d Abortion Cost $<0$ ). But one of the major advances in the recent abortion literature is the recognition that increases in abortion costs may also have a negative effect on the number of pregnancies in the abortion rate $(\partial$ Number of Pregnancies/O Abortion Cost $<0$ ). This suggests that estimates of the impact of restrictive abortion laws using the abortion ratio as the dependent variable may underestimate their numerical impact since restrictive abortion laws may have a spillover effect reducing the number of unintended pregnancies, some which would have resulted in an abortion.

In addition, the use of either the abortion rate or the abortion ratio as the dependent variable suffers from a methodological problem. Previous estimates of the effect of restrictive abortion laws on the abortion ratio may have underestimated their numerical impact since the total number of pregnancies in the denominator of the abortion ratio is the sum of intended pregnancies and unintended pregnancies. Women with intended pregnancies are virtually certain they want to have a child and thus are not affected by restrictive abortion 
laws, which biases the impact of restrictive abortion laws downwards toward zero.

Similarly, previous estimates of the impact of restrictive abortion laws on the abortion rate may have underestimated their numerical impact since the total number of women of childbearing age in the denominator of the abortion rate includes women who are not sexually active and women who are sexually active and practice safe or unsafe sex. Women of childbearing age who are not sexually active and, to a lesser extent, women who are sexually active and practice safe sex are not affected by restrictive abortion laws, which biases the estimated numerical impact of restrictive abortion laws, using the abortion rate as the dependent variable, downwards.

\section{LOCATION OF THE ABORTION PROCEDURE}

State data on the number of abortions is available from two different sources: the Centers for Disease Control (CDC) and the Guttmacher Institute (GI). The CDC publishes state abortion numbers, on an annual basis, based upon figures provided by state public health departments, whose collection practices vary considerably. The CDC acknowledges that its state abortion figures are incomplete and underreported. The GI conducts periodic surveys of abortion providers as to how many abortions they performed. The GI uses a consistent collection methodology, but it does not collect state abortion data every year. Because the GI intensively surveys both large and small abortion providers their data is generally recognized (even by the CDC) as the most accurate and comprehensive available.

Both the CDC and the GI abortion figures are reported only by the state in which the abortion was performed (state of occurrence) rather than by the state of residence of the women who had the abortion. The problem with using state of occurrence abortion figures is that they ignore interstate travel by women to nearby adjacent states to circumvent a restrictive abortion law in their state. Women may respond to a restrictive abortion law by obtaining an abortion from an out-of-state provider without such a law. The effect of a restrictive abortion law may be to merely change the location of the abortion procedure rather than reduce the incidence of abortion.

The use of state of occurrence abortion data creates an upward bias (a larger impact than actually exists) in the estimates of the impact of restrictive abortion laws on the incidence of abortion because abortion rates are underestimated in those states with restrictive abortion laws and overestimated in contiguous states without such laws. The extent of this bias depends upon how extensive is travel by women to adjacent states to obtain an abortion.

The CDC reported that interstate travel by women to obtain an abortion is substantial - in 2007, out-of-state residents accounted for $8.5 \%$ of all abortions. The percentage of abortions obtained by out-of-state residents ranged from $47.8 \%$ in Kansas to $.5 \%$ in Hawaii. Out-of-state residents accounted for more than $10 \%$ of abortions in 16 states. In Delaware and North Dakota, out-of-state residents accounted for more than $29 \%$ of all abortions performed. In Wyoming, residents had 839 abortions, but only 9 were performed in Wyoming. In Mississippi, one of the most antiabortion states in the United States, residents had 6616 abortions, but only 2932 were performed in Mississippi.

Thus, in estimating the impact of various restrictive state abortion laws on the incidence of abortion, travel by women across state lines to obtain an abortion must be controlled for by including in a model, border state policy variables that measure the abortion policies of all physically contiguous states.

\section{THE IMPACT OF RESTRICTIVE STATE ABOR- TION LAWS}

There are six types of restrictive state abortion laws that the Supreme Court has held to be constitutionally permissible.

\subsection{No Medicaid Funding}

Medicaid is a federal and state health insurance program that jointly funds medical services for the poor in each state. In 1980, the Supreme Court in Harris v. McRae ruled that an amendment passed by Congress in 1976 (i.e., the Hyde amendment) that prohibited the use of federal funds to pay for Medicaid abortions for poor women in each state was constitutional. The decision of whether or not to fund Medicaid abortions was left to the sole discretion of each state. Many states enacted laws that prohibited the use of their public funds to pay for Medicaid abortions for lowincome women. State laws prohibiting the funding of Medicaid abortions increase the costs of abortion services for lowincome women. In 2013, 33 states had enacted laws prohibiting the use of their public funds to pay for Medicaid abortions. In those 33 states, poor women must pay the entire out-of-pocket cost for an abortion. As a consequence, one would expect the demand for abortion in those states to be lower, other things equal.

Table 1 provides a summary of studies that used, the most common research method, multivariate regression models to estimate the impact of Medicaid funding restrictions on the demand for abortion. Studies that used pooled cross-section time-series data typically included indicator (dummy) variables for each state and year (i.e., state and year fixed effects). It is important to point out that the reason that researchers include state-specific fixed effects in their models is an attempt to control for omitted variable bias. There may exist unobserved or unmeasured differences in a state's attitudes or beliefs or sentiment about abortion that are correlated with a state's abortion policies. If this occurs, then the relationship between a restrictive abortion law and a state's abortion rate would not be causal, but as a result of a state's abortion policies being correlated with these unobserved or unmeasured factors within a state which, in turn, influence women's abortion decisions, resulting in spurious estimates of the effects of restrictive abortion laws. The econometric technique, used with virtual unanimity by all researchers who analyze pooled cross-section time-series data, is to include state-specific fixed effects (a dummy variable equal to one for each of 49 states). It is assumed, explicitly or implicitly, that state-specific fixed effects control for these unobserved or unmeasured time-invariant differences across states in antiabortion sentiment or attitudes, which may induce changes in women's sexual behavior and/or pregnancy resolution decisions. However, it should be noted 
Table 1. Estimates of the Numerical Impact of a Medicaid Funding Restriction on State Abortion Rates of Women of Childbearing Age, 15-44 Years

\begin{tabular}{|c|c|c|c|c|}
\hline Author(s) & Data Source & Study Years & Estimation Method & Numerical Impact On Abortion Rate \\
\hline \hline Medoff [10] & GI & 1982 & 2SLS & $-4.4 \%$ \\
\hline Blank et al. $[5]$ & GI & $1974-1988$ & OLS, 2SLS & $-5 \%$ \\
\hline Levine et al. $[6]$ & GI & $1977-1988$ & Weighted OLS & $-5.5 \%$ \\
\hline Haas-Wilson [8] & GI & $1978-1992$ & Weighted OLS & $-2 \%$ \\
\hline Matthews et al. $[9]$ & GI & $1978-1988$ & Weighted OLS & n.s. \\
\hline Bitler and Zavodny [7] & GDC & $1974-1997$ & Weighted OLS & $-3.3 \%$ \\
\hline Medoff [11] & GI & $1982,92,2000$ & 2SLS & $-4 \%$ \\
\hline Medoff [12] & GI & $1982,92,96,20002005$ & 2SLS & \\
\hline
\end{tabular}

Note: The dependent variable in all the above studies is the abortion rate (the number of abortions per 1000 women of reproductive age $15-44$ years) for all states. n.s. $=$ not significant; 2SLS=Two-Stage Least-Squares; OLS= Ordinary Least-Squares; GI= Guttmacher Institute; CDC= Centers for Disease Control.

that a state-specific fixed effects model may be merely measuring the effects of some of the explanatory variables that are poorly measured or specified, inadequate proxies or omitted from the model because of the unavailability of data. In addition, a state-specific fixed effects model implicitly assumes that these unobserved, unmeasured or omitted factors that are specific to each state are constant or unchanged over time.

Blank et al. [5] found that, over the period 1974-1988, a Medicaid funding restriction reduced the number of abortions among poor women by 19-25 percent. This translates into a decrease of 5 percent in a state's overall abortion rate, which is a magnitude similar to that found by Levine et al. [6]. Other studies [7-12] using different estimation techniques, time periods and model specifications found that a Medicaid funding restriction reduced a state's abortion rate by between 3-4 percent.

Cook et al. [13] used individual-level date from North Carolina to estimate the impact of the lack of availability of public funds from North Carolina's separate state abortion fund for indigent women. Over the time period 1980-1993, there were five periods during which funding of abortions for poor women from this fund was unavailable. They found that abortion rates decreased and birthrates increased for indigent women during these five time periods. They estimated that there were 1 percent fewer abortions for white women and 10 percent fewer abortions for black women. They concluded that 37 percent of Medicaid-eligible pregnant women, who would have had an abortion if funds had been available, carried their pregnancy to term.

Morgan and Parnell [14] expanded the empirical work of Cook et al. and focused on the unavailability of state abortion funds in North Carolina over the period 1988-1995. They found that the proportion of Medicaid-eligible white women who carried their pregnancies to term in the absence of funding from the North Carolina State Abortion Fund ranged from 29 percent for those younger than 18 years of age to 68 percent for those 30 years or older. The percentage of Medicaid-eligible blacks who carried their pregnancies to term ranged from 26-29 percent for those younger than 22 years of age and 16-20 percent for those 22 years or older.
Even though these two studies only apply to North Carolina, both studies find that restrictions on Medicaid funding are associated with a decrease in abortions and an increase in the percentage of pregnancies carried to term for indigent pregnant women.

In general, the empirical results corroborate the theoretical prediction that restricting the state funding of Medicaid abortions decreases the demand for abortions. A state Medicaid funding restriction decreases a state's abortion rate of women of childbearing age (15-44 years) by no more than 36 percent. However, there are several limitations with the studies listed in Table $\mathbf{1}$ that use pooled cross-section timeseries multivariate regression models to estimate the impact of Medicaid funding restrictions on state abortion rates that should be noted.

First, there is the problem of misclassification. As of 2013, there are 17 states that use their own public funds to pay for Medicaid abortions. Four states (Hawaii, Maryland, New York, Washington) did so voluntarily. The other 13 states (Alaska, Arizona, California, Connecticut, Illinois, Massachusetts, Minnesota, Montana, New Jersey, New Mexico, Oregon, Vermont, and West Virginia) were ordered by their state courts to pay for Medicaid abortions. But, several of these states classified as funding Medicaid abortions, in fact, funded very few Medicaid abortions. For example, in 2005, Arizona funded 7 and Illinois funded 25 Medicaid abortions. This raises the obvious question, which virtually all researchers fail to address, of whether such states should be classified as restricting Medicaid funding of abortions. Second, there has been very little variation in the enactment of Medicaid funding restrictions by states. Virtually all the states that enacted Medicaid funding restrictions did so by the early 1980s. Since 1995, only three states (Montana in 1995, New Mexico in 1998 and Arizona in 2002) changed from a Medicaid funding restriction state to a state that funds Medicaid abortions. This lack of variation makes it difficult for researchers to determine whether a decline in abortion rates was due to a time trend (greater use of contraception, more efficacious contraceptive methods, possible contraction of AIDS) or a Medicaid funding restriction. Third, many of the states that were the first to enact a Medicaid funding restriction were also the states whose residents had the most 
antiabortion attitudes (e.g., Alabama, Mississippi, Utah). These states were also the most likely to enact an array of additional abortion restrictions, making it difficult to determine if a decline in abortion rates was due to the Medicaid funding restriction or these other potentially confounding abortion restrictions. Fourth, none of the states listed in Table 1 interacted their indicator variable $(=1)$ for the presence of a Medicaid funding restriction with the number of women of reproductive age (15-44 years) on Medicaid. A Medicaid funding restriction only affects women of reproductive age on Medicaid, who represent only a very small proportion of all women of reproductive age. In 2005 , only 11.8 percent of all women of reproductive age were on Medicaid in Medicaid funding restriction states and 16 states had less than 11 percent of women of reproductive age on Medicaid. But, even these figures overstate the impact of a Medicaid funding restriction since the funding restriction only affects pregnant women who are a much smaller subset of women of reproductive age on Medicaid.

\subsection{Parental Involvement Laws}

Since the 1973 Roe v. Wade decision, the Supreme Court in a number of cases (e.g., Planned Parenthood of Central Missouri v. Danforth (1976); Bellotti v. Baird (1979)) held that unmarried teen minors (less than eighteen years of age) have a constitutional right to obtain an abortion, but their reproductive rights are limited. It is constitutionally permissible for a state to require that a parent be involved in a teen minor's abortion decision. Parental involvement laws require that a parent be notified or give permission before an unmarried teen minor can obtain an abortion. Parental involvement laws increase the emotional cost as well as the out-of-pocket expenses of a teen minor obtaining an abortion.

Some studies have examined the question of the impact of parental involvement laws on teen minors' pregnancy resolution decisions indirectly. Levine [15], using the Youth Risk Behavior Survey (which has very few measures of individual socioeconomic characteristics) found that over the period 1991-1997 a parental involvement law had no impact on the probability of teen sexual activity. Similarly Averett et al. [16], using the 1995 National Surveys of Family Growth, found that a parental involvement law had no effect on the sexual activity of teens. Levine [17], using the 1988 and 1995 National Surveys of Family Growth, found that the enforcement of a parental involvement law increases the probability of safe sexual activity (although the coefficient estimates are only marginally statistically significant depending on the model specification), but has no effect on the frequency of teen sexual activity. Sen [18], using the $1997 \mathrm{Na}-$ tional Longitudinal Survey of Youth, found that a parental involvement law had no significant impact on either the frequency of sexual activity or the frequency of noncontracepted sexual activity of teen minor girls.

Studies that use individual-level survey data suffer from several methodological shortcomings. First, self-reported data on sexual activity is notoriously unreliable. Considerable measurement error exists in the responses to a sex survey due to untruthful, incorrect, exaggerated and unreliable answers to intimate questions about a personal and private area of one's life. Second, survey data typically contains very little information about an individual's personal charac- teristics, particularly economic information. Third, most sex surveys ask respondents only if they were, or were not, sexually active during the past three months and ignore the frequency and regularity of sexual activity.

Other studies have examined the enforcement of a parental involvement law on teen minor abortion rates in individual states and find either a very small or no impact on teen minors' demand for abortion. Cartoff and Klerman [19] and Henshaw [20] found that a parental involvement law had no impact on teen minor abortion rates in Massachusetts and Mississippi, respectively, because of travel by minors to nearby states. Ellertson [21], using individual-level data for teen minors in Minnesota, Missouri and Indiana found that parental involvement laws did cause a statistically significant decrease in teen minor abortion rates. Ellertson suggested that the observed declines could have been due to travel by resident teen minors to nearby states. Joyce and Kaestner [22] examined individual-level abortion data of teen minors in South Carolina and Mississippi. They found that, in South Carolina, the enforcement of a parental involvement law had no significant effect on the timing or the location of the abortion procedure of teen minors as compared to non-minor teens. In Mississippi, the parental involvement law was associated with a decrease in the number of abortions and an increase in the proportion of out-of-state abortions of minor teens as compared to non-minor teens. However, the decrease in the number of abortions did not result in a statistically significant increase in births to teen minors. Rogers et al. [23] found that teen minor abortion rates decreased slightly after Minnesota enforced a parental involvement law. However, the authors did not take into account interstate travel by teen minors to obtain abortions out-of-state. Joyce and Kaestner [24] found that a parental involvement law enacted in South Carolina had a very small numerical decrease in teen minors' abortion rate. The authors suggested that this was because teen minors included a parent in their pregnancy resolution decision or traveled to a neighboring state without a parental involvement law for an abortion. Joyce et al. [25] assessed changes in the rate of teen minor abortions before and after the enforcement of a parental involvement law in Texas. After enforcement of the parental involvement law, the abortion rate of teen minors (15-17 years of age) decreased between 11-20 percent as compared to teens eighteen years of age. Similarly, Colman et al. [26] found that Texas' parental involvement law was associated with a 15 percent reduction in the abortion rate of 17 yearolds relative to 18 year-olds, based on the age at the time of conception.

Other studies have used pooled cross-section time-series data to examine the impact of parental involvement laws on state abortion rates of all women of childbearing age 15-44 years or teen minors 15-17 years of age. Table $\mathbf{2}$ provides a summary of these studies. Blank et al. [5] found that parental involvement laws had no statistically significant impact on the abortion rate of women of childbearing age (15-44 years). Matthews et al. [9] and Bitler and Zavodny [7] reported that parental involvement laws reduced the abortion demand of women of childbearing age by $3.2 \%$ and $5.5 \%$, respectively, when a state and year fixed effects model was used. But Haas-Wilson [8] found that, over the time period 1978-1997, the effect of a parental involvement law on the abortion demand of women of childbearing age was statisti- 
Table 2. Estimates of the Numerical Impact of a Parental Involvement Law on State Abortion Rates

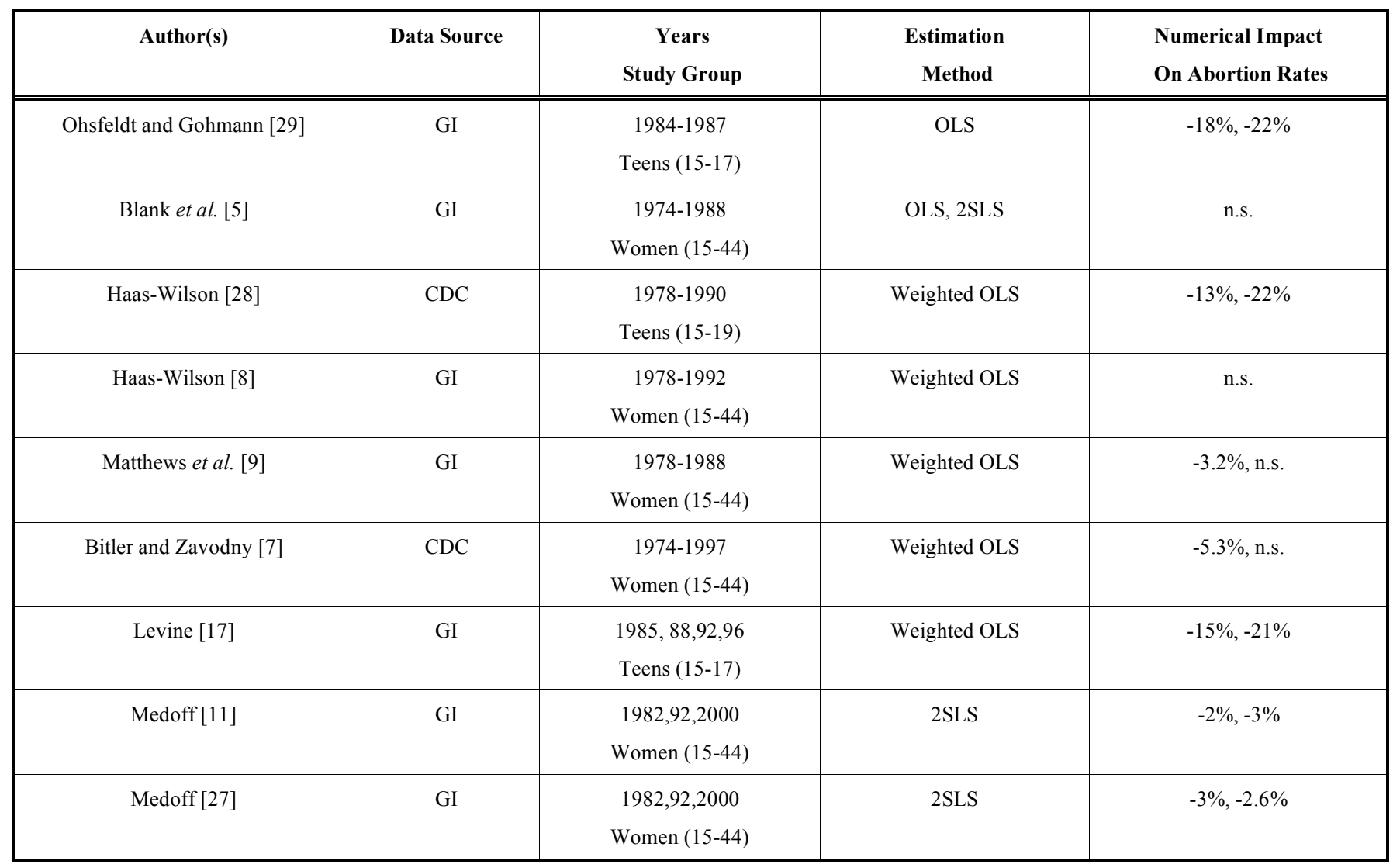

Note: The dependent variable in all the above studies is the abortion rate (the number of abortions per 1000 women of reproductive age or teens) for all states. n.s. $=$ not significant; 2SLS=Two-Stage Least-Squares; OLS= Ordinary Least-Squares; GI= Guttmacher Institute; CDC= Centers for Disease Control.

cally insignificant. Medoff $[11,27]$ found that a parental involvement law reduced the abortion demand of women of childbearing age by a numerically small magnitude $(.3 \%$ to $3 \%$ ). Haas-Wilson [28] and Levine [17] reported that parental involvement laws reduced the abortion demand of teens (15-19) by between $13 \%$ and $22 \%$ and teen minors (15-17) by between $15 \%$ and $21 \%$. Ohsfeldt and Gohmann [29] found that parental involvement laws decreased the ratio of abortion rates of teen minors (15-17) to older teens (18-19) by $22 \%$.

The empirical results of these studies on the impact of parental involvement laws are ambiguous and contradictory for a number of reasons. (1) Many of the studies listed in Table 2 had classification errors- categorizing states as having a parental involvement law when, in fact, the state did not have a parental involvement law. For example, several of the states listed in Table 2 classified Connecticut as having a parental involvement law in effect over the period 19901997. Connecticut has never had a parental involvement law. Connecticut has an emancipated minor statute which requires that a physician or counselor give a teen minor objective information about abortion and its alternatives and discuss the "possibility" of involving her parents or other adult family members in her decision-making. But, if the teen minor declines, no parental consent or parental notification is required. (2) Several of the studies listed in Table 2 categorized states as having a parental involvement law, even though when the state enacted the parental involvement law, the law was enjoined and the state was unable to enforce the parental involvement law until a definitive decision was reached by the state's Supreme Court or a federal Appeals Court at a much later date. The result was a substantial number of misclassification errors. (3) Parental involvement laws may be merely symbolic and not binding if teen minors routinely involve a parent in their pregnancy resolution decision. Henshaw and Kost [30] reported that 61 percent of teenage girls, who became pregnant, voluntarily told a parent. (4) The laws vary widely in their degree of involvement. Some states allow grandparents, adult relatives or other specified health professionals or counselors to be involved in a teen minor's abortion decision. (5) Teen minors are able to circumvent a parental involvement law by traveling to neighboring states without such a law, which diminishes the impact of a parental involvement law. A parental involvement law may merely change the location of the abortion procedure rather than reduce the incidence of teen minor abortion. But most studies fail to control for interstate travel. (6) All these studies use state of occurrence abortion data (where the abortion is performed). State of occurrence data overestimates the impact of a parental involvement law not only because of resident teen minors traveling to nearby states without a parental involvement law, but also because of a decrease in nonresident teen minors traveling to the state for an out-of-state abortion. (7) Since teen minor abortions represent less than $8 \%$ of all abortions, parental involvement laws may have only a numerically or statistically insignificant impact of the overall incidence of abortion. 


\subsection{Mandatory Counseling Laws}

All states require healthcare providers, prior to performing a nonemergency medical procedure, provide germane information to and obtain medical consent from patients about the medical procedure. However, in addition to the general informed consent requirements, many states enacted additional mandatory counseling laws that apply only to abortion. In 2013, 27 states had their state health agencies develop written materials about abortion. These abortionspecific counseling laws require that an abortion provider, usually 24 hours before the procedure is performed, give or offer to women the state-written abortion-specific medical information about abortion. Although the content of the abortion information varies from state to state, it generally covers such topics as fetal development, gestational age of the fetus, future health risks, adoption options and available public assistance. The implicit intent of a mandatory counseling law is to increase the emotional costs to woman and dissuade women from terminating an unintended pregnancy.

Researchers examining whether mandatory counseling laws dissuade pregnant women from having an abortion face many of the same methodological problems that affect the examination of Medicaid funding restrictions and parental involvement laws. First, there is the misclassification problem. All 50 states, by statute or case law, have a general mandatory counseling requirement that applies to all medical procedures, not just abortion. As of 2013, 35 states require that women receive counseling before an abortion is performed. However, in 8 of these states, the healthcare provider imparts general information about the procedure and risks to patients. The other 27 states have detailed mandatory abortion-specific state written information about abortion. Many studies incorrectly classify all 35 states as having a mandatory counseling law. Second, 10 of these 27 states require that the written materials must be given to the woman and in the other 17 states the written materials are offered to the woman, who may decline to take it. In addition, there is no requirement that women must actually read any written materials they receive in any of these 27 states. Third, the method of delivery of the written materials varies considerably from state to state. The written materials may be furnished to women by mail, fax, the Internet or read over the phone or delivered by a recorded message. Fourth, the content of the written materials also varies considerably between states. Some states require information on the ability of the fetus to feel pain, life begins at conception, potential future health risks including suicide, eating disorders, drug abuse and breast cancer. Fifth, in some states abortion providers are specifically allowed to disassociate themselves from the medical information in the written materials, although they are still required to provide them to patients. Sixth, in some states the content of the state-mandated abortion-specific written information has changed over time. As a consequence, there is a considerable amount of variation in mandatory counseling laws within a particular state as well as between states.

Joyce [31] examined the impact of Texas' Woman's Right to Know Act enforced on January 1, 2004. The Texas Right to Know Act required that at least 24 hours before an abortion is performed, women receive information about the procedure and alternatives to abortion. The information could be furnished to women by a telephone recording, a video or in person. The Act also required that women be offered a pamphlet that graphically illustrates the growth of a fetus during pregnancy. Joyce found that the number of abortions performed and the abortion rate of women with pregnancies less than 16 weeks of gestation in 2004 showed no significant statistical or numerical decrease from 2003. As noted by Joyce, the Texas mandatory counseling law had no measurable impact on the incidence of abortion prior to 16 weeks of gestation.

Similarly, Medoff [27], using pooled cross-section timeseries data over the time period 1982-2000, found that mandatory counseling laws had no significant impact on the abortion rate of women of childbearing age. In addition, there are 17 states that mandate that women be given written information about the following rare, nonexistent or false side effects from having an abortion: (i) a purported link between abortion and breast cancer; (ii) the ability of the fetus to feel pain; (iii) long-term negative mental health outcomes (i.e., eating disorders, drug abuse, suicide, depression, sexual dysfunction, mental instability); and (iv) infertility. Medoff [32] investigated whether any of these four abortion falsehoods had an impact on the demand for abortion in the year 2000. The empirical results found that these four abortion falsehoods had no significant impact on the abortion demand of pregnant women of childbearing age (15-44 years), adult pregnant women (18-44 years) or pregnant teen minors (15-17 years). The empirical results remained robust even after controlling for regional differences in antiabortion attitudes.

The consistent finding is that mandatory counseling laws have no significant impact on abortion demand. Very few pregnant women seeking an abortion are dissuaded by mandatory counseling laws.

\subsection{Mandatory Waiting Period Laws}

As of 2013, 23 states required a waiting period of 24 hours, one state required a waiting period of 18 hours, another required a period of 72 hours and one state required one day between when a woman receives the counseling information and the abortion procedure is performed. Proponents of waiting periods argue that their purpose is to allow a woman to consider all her options after being given the counseling information about abortion. In most states that require mandatory counseling, the abortion provider does not have to furnish the state-approved medical information in person. However, ten states have two-visit laws that require women receive their mandatory counseling information in person at least 24 hours before the abortion procedure. Twovisit waiting period laws necessitate that women make two separate trips to the abortion provider which imposes substantial travel expenses and time costs on women seeking an abortion.

The research on the impact of mandatory waiting period laws falls into two groups: case studies that focused exclusively on Mississippi and pooled cross-section time-series analysis that focused on overall abortion rates. Althaus and Henshaw [33], Joyce et al. [34] and Joyce and Kaestner [22, 35] found that Mississippi's two-visit law was associated with a decrease in the number of abortions performed in Mississippi by 10-14 percent, an increase in the number of 
out-of- state abortions performed on Mississippi residents and an increase in the number of abortions performed during the second trimester of pregnancy to Mississippi residents.

Medoff [27, 36, 37] found that, over the time period 1982-2005, mandatory waiting periods in general and twovisit laws in particular have no effect on the overall incidence of abortion. Similarly, Bitler and Zavodny [7] found that, over the period 1974-1997, mandatory waiting periods had no significant effect on the overall abortion rate, but did increase the percentage of abortions performed after the first trimester of pregnancy. However, Bitler and Zavodny's and Medoff's study suffer from the problem that their abortion data is only available by state of occurrence. This use of state of occurrence data biases the empirical results toward finding either no change or a small decline in the abortion rate if women leave their state of residence in order to obtain an abortion in a contiguous state and nonresidents no longer travel to the state to obtain an out-of-state abortion.

Notwithstanding this caveat, these empirical results suggest that mandatory waiting periods/two-visit laws represent a negligible increase in the total cost of obtaining an abortion to women. This empirical result is not surprising. Even though 87 percent of U.S. counties are without an abortion provider, abortion services tend to be concentrated in large metropolitan areas, which have a greater number of women of childbearing age, which reduces women's travel, time and search costs of obtaining an abortion. Jones et al. [38] reported that in 2005, 73 percent of women traveled less than 50 miles (approximately one hour of travel) and 19 percent traveled 50-100 miles to obtain an abortion. These figures suggest that roughly 90 percent of women live within a 90minute drive to an abortion provider and virtually all women live within a 2-3 hour drive to an abortion provider.

\subsection{TRAP Laws}

Many states have enacted Targeted Regulation of Abortion Provider laws (more commonly known by the acronym TRAP laws) which apply only to abortion providers and impose on them a wide variety of burdensome and onerous requirements not imposed on those performing comparable medical services. The two most common state TRAP laws are health facility licensing requirements and physical/administrative requirements. TRAP licenses require that any physician, facility or organization that performs abortions must pay an annual fee to obtain a license, retain certain records and reports, maintain quality assurance programs and written safety rules for drugs, gases, liquids, etc. TRAP physical plant/administrative laws impose on abortion providers unnecessary, nonessential and cumbersome plant and personnel requirements that regulate wide-ranging aspects of abortion providers' operations. For example, Missouri requires that the facilities of abortion providers must be located within 30 miles of a hospital and have procedure rooms that are at least 12 feet long and 12 feet wide, with ceilings at least 9 feet high and doors at least 44 inches wide. Connecticut requires that all abortion providers must employ counselors who have or are supervised by a person with a graduate degree in social work, psychology, counseling or ministry. According to abortion rights supporters, TRAP laws serve no legitimate health purposes and the implicit goal of TRAP laws is to drive abortion providers out of business and reduce the supply of abortion services.

There has been very little research on the effect of TRAP laws because they have only been enacted since the Supreme Court's 1992 Casey decision. The Texas Women's Right to Know Act referred to in the previous section also had a supply-side component. The supply-style component required that all abortions on or after 16 weeks of gestation be performed in an ambulatory surgical center. Ambulatory surgical centers have more stringent staffing, reporting, and physical facility requirements than freestanding abortion clinics. Joyce [31] and Colman and Joyce [39] examined the impact of this supply-side policy. When the Act went into effect on January 1, 2004, none of Texas' 54 non-hospital abortion providers qualified as an ambulatory surgical center and the result was a substantial decline in the availability of abortion services after 15 weeks of gestation in Texas.

They found that the number of abortions performed in Texas at or after 16 weeks of gestation declined by 88 percent from 2003 to 2004, while the number of Texas residents who left the state for a second trimester abortion increased by nearly 300 percent. The net effect was that there was a 68 percent decrease in the number of abortions at 16 weeks or later performed on Texas residents one year after the law took effect. Similarly, Jones and Weitz [40] reported that a TRAP law enacted in Mississippi in 2005, requiring that second-trimester abortion providers must comply with all ambulatory surgical center regulations, caused the only outpatient abortion provider in Mississippi to stop providing abortions after 12 weeks of gestation resulting in many unwanted births.

Fewer abortion providers increase both women's search costs of locating an abortion provider and the travel and time costs associated with obtaining an abortion. Prior research has found that an increase in the full cost of obtaining an abortion due to an increase in women's search costs of locating an abortion provider and/or an increase in the travel distance or time costs to the nearest abortion provider will decrease the quantity of abortions demanded [41, 42]. Medoff [12] examined whether a state TRAP licensing fee or a TRAP plant/personnel law had an independent impact on women's demand for abortion over the time period 19822005. The empirical results found that neither TRAP law had a significant independent negative impact on women's pregnancy resolution decisions. Nor did either TRAP law have a spillover effect on women's demand for abortion by causing an increase in the price charged by abortion providers.

\subsection{Partial-Birth Abortion Bans}

Between 1997 and 2000, 13 states enacted laws banning a specific late-term and infrequently used medical abortion technique called dilation and extraction and described colloquially as "partial-birth abortion". In 2000, the Supreme Court in Stenberg v. Carhart struck down all the laws because the descriptions of the medical procedure was so broad and vague that they excluded many conventional abortion techniques and many of the bans did not include a medical exception to protect a pregnant woman's life or health. In 2007, the Supreme Court (with several new members) reversed itself in Gonzales v. Carhart and upheld the federal Partial-Birth Abortion Ban Act of 2003, which prohibited the 
dilation and extraction abortion technique, even though the Act did not have a medical exception to protect a women's life or health.

New [43], in a Heritage Foundation report, found that a partial-birth abortion ban law had a significantly negative effect on state abortion rates over the years 1985-1999. Gius [44], using individual-level data from the 1997 National Longitudinal Survey of Youth, found that a partial-birth abortion ban law had no significant effect on a woman's pregnancy resolution decision. The problem with both these studies is that states that enacted laws banning the partialbirth abortion technique were never able to enforce their laws because they were all enjoined in federal court from going into effect. Thus, the partial-birth abortion ban variable in both studies is a proxy for some other omitted variable such as antiabortion attitudes in a state.

\section{DISCUSSION}

This paper focused on the positive question: what is the impact of restrictive state abortion laws on abortion rates? Since the Supreme Court's 1973 decision legalizing abortion, states have enacted six constitutionally permissible laws restricting women's access or availability of abortion: No Medicaid Funding, Parental Involvement Laws, Mandatory Counseling Laws, Mandatory Waiting Period Laws, Targeted Regulation of Abortion Providers (TRAP laws) and "Partial-Birth Abortion Bans".

The theoretical model of fertility control posits that women weigh the costs and benefits on whether to have an abortion or give birth if pregnant and how intensively to use contraception. For pregnant women, a birth may be unwanted and impose certain costs on them. These women would terminate the pregnancy if the full cost of an abortion is less than the cost of having an unwanted child. The full cost of an abortion includes the direct monetary costs (i.e., out-of-pocket cost of the procedure, travel expenses, childcare expenses) and the indirect costs (i.e., emotional costs such as shame, regret, guilt, trauma). Restrictive abortion laws increase the full cost of an abortion and the predicted effect is fewer abortions. However, this predicted negative effect depends crucially on whether the increase in the full cost of an abortion, due to the enforcement of a restrictive abortion law, is substantial and substantive.

Notwithstanding the limitations and reservations noted in this paper, a clear trend emerges from this review of the abortion literature. The empirical evidence indicates that mandatory counseling and waiting period laws have no significant impact on women's pregnancy resolution decisions. The reason is that there is no requirement that women actually read the state-mandated written materials given to them about abortion and most women live within a 90-minute drive to an abortion provider. Parental involvement laws have only a very small numerical impact on teen minors' decisions to have an abortion because teen minors typically involve a parent in their decisions and/or teen minors can circumvent a parental involvement law by traveling to a nearby state without such a law. Laws restricting a state's funding of Medicaid abortions lower a state's abortion rate by no more than 1 to 3 percent because these laws only affect the small subset of low-income women of childbearing age who are pregnant. The ban on the partial-birth abortion technique has no impact on abortion rates because typically the procedure was only performed during the second trimester of pregnancy when fetal abnormalities are detected. Taken together, the body of empirical research reported in this paper suggests that state abortion rates are largely unaffected by these five demand-side policies. These demandside antiabortion laws dissuade very few pregnant women seeking an abortion.

The findings of this review also suggest that future research is needed to study the impact of Targeted Regulation of Abortion Providers (TRAP) laws. Increasingly, states are enacting TRAP laws that attempt to impact the supply-side of abortion. TRAP laws subject abortion providers to a wide variety of licensing regulations or requirements governing their physical plant, staffing requirements and qualifications, and protocols not imposed on other comparable medical practitioners (e.g., fertility physicians, obstetricians and gynecologists who do not perform abortions).

States (and opponents of abortion) argue that the rationale for enacting TRAP laws is to advance, promote and protect the health and lives of pregnant women seeking an abortion. Abortion rights supporter maintain that the implicit or explicit intent of TRAP laws is, by imposing medically unnecessary, burdensome and costly regulations on abortion providers, deter physicians from becoming providers or drive abortion providers out of practice and make abortion services more difficult for women to obtain.

Opponents of abortion have shifted their focus from demand-side policies, which directly target women, to the enactment of TRAP laws because TRAP laws affect only abortion providers' facilities and not the constitutional right of a woman to make the decision to have an abortion. Yet, there has been very little research on the impact of TRAP laws on the supply-side of the abortion market. One exception is Medoff [45] who found that TRAP laws had a substantial negative impact on the number of abortion providers in a state. The numerical impact of a state TRAP law was to reduce the number of abortion provider facilities by 15.5 per 100,000 pregnancies as compared to states without TRAP laws.

The paucity of research on the supply-side of the abortion market is not because there is no data available. The Guttmacher Institute periodically conducts a thorough survey of the number of abortion providers. However, research on the supply-side of the abortion market is mainly descriptive, documenting changes in the number of abortion providers.

The number of abortion providers and the geographical distribution of abortion providers are important determinants of women's access to abortion. Greater geographical availability of abortion providers impacts women's demand for abortion by reducing the search costs, travel time and out-ofpocket travel expenses associated with obtaining an abortion. Whether TRAP laws impose an unambiguous undue burden on women seeking an abortion by reducing their access to abortion services and inhibiting their reproductive choices is an issue that future research needs to address.

\section{CONFLICT OF INTEREST}

The authors confirm that this article content has no conflicts of interest. 


\section{ACKNOWLEDGEMENT}

Declared none.

\section{REFERENCES}

[1] Becker GS. An economic analysis of fertility. In Christ C. Ed. Demographic and Economic Change in Developed Countries. Princeton, NJ: Princeton University Press 1960; pp. 209-31.

[2] Michael RT. Education and the derived demand for children. J Polit Econ 1973; 81(2): 128-64.

[3] Willis RJ. A new approach to the economic theory of fertility behavior. J Polit Econ 1973; 81(2): 14-64.

[4] Kane TJ, Staiger D. Teen motherhood and abortion access. Q J Econ 1996; $111(2)$ : 467-506.

[5] Blank RM, George CC, London RA. State abortion rates: the impact of policies, providers, politics, demographics, and economic environment. J Health Econ 1996; 15(5): 513-53.

[6] Levine PB, Trainor AB, Zimmerman DJ. The effect of Medicaid abortion funding on abortions, pregnancies and births. J Health Econ 1996; 15(5): 555-78.

[7] Bitler M, Zavodny M. The effect of abortion restrictions on the timing of abortions. J Health Econ 2001; 20(6): 1011-32.

[8] Haas-Wilson D. Women's reproductive choices: the impact of Medicaid funding restrictions. Fam Plann Perspect 1997; 29(5): 228-33.

[9] Matthews D, Ribar D, Wilhelm M. The effects of economic conditions and access to reproductive health services on state abortion rates and birthrates. Fam Plann Perspect 1997; 29(2): 52-60.

[10] Medoff $\mathrm{MH}$. An economic analysis of the demand for abortions. Econ Inq 1988; 36(3): 353-9.

[11] Medoff MH. Price, restrictions and abortion demand. J Fam Econ Iss 2007; 28(5): 583-99

[12] Medoff MH. State abortion policies, targeted regulation of abortion providers laws and abortion demand. Rev Polit Res 2010; 27(5): 577-94.

[13] Cook PJ, Parnell AM, Moore MJ, Pagnini D. The effects of shortterm variation in abortion funding on pregnancy outcomes. J Health Econ 1999; 18(2): 241-57.

[14] Morgan SP, Parnell AM. Effects on pregnancy outcomes of changes in the North Carolina state abortion fund. Popul Res Polit Rev 2002; 21(4): 319-38.

[15] Levine PB. Activity and birth control use of American teenagers. In: Gruber J Ed. An economic analysis of risky behavior among youths. Chicago, Illinois: University of Chicago Press 2001; pp. 167-218.

[16] Averett SL, Rees DI, Argys LM. The impact of government policies and neighborhood characteristics on teenage sexual activity and contraceptive use. Am J Public Health 2002; 92(1): 1773-8.

[17] Levine PB. Parental involvement laws and fertility behavior. J Health Econ 2003; 22(5): 861-78

[18] Sen B. Frequency of sexual activity among unmarried adolescent girls: do state policies pertaining to abortion access matter? East Econ J 2006; 32(2): 313-30.

[19] Cartoff VG, Klerman LV. Parental consent for abortion: impact of the Massachusetts law. Am J Public Health 1986; 76(4): 397-400.

[20] Henshaw SK. The impact of requirements for parental consent on minors' decisions in Mississippi. Fam Plann Perspect 1995; 27(3): 120-2.

[21] Ellertson C. Mandatory parental involvement in minors' abortions: effects of the laws in Minnesota, Missouri and Indiana. Am J Public Health 1997; 87(8): 1367-74.
Joyce T, Kaestner R. The impact of mandatory waiting periods and parental consent laws on the timing of abortion and state of occurrence among adolescents in Mississippi and South Carolina. J Polit Anal Manage 2001; 20(2): 263-82.

[23] Rogers J, Boruch R, Storms G, DeMoya D. Impact of the Minnesota parental notification law on abortion and birth. Am J Pub Health 1991; 81(3): 294-98.

[24] Joyce T, Kaestner R. State reproductive policies and adolescent pregnancy resolution: the case of parental involvement laws. J Health Econ 1996; 15(5): 579-607.

[25] Joyce T, Kaestner R,. Changes in abortions and births and the Texas parental notification law. New Eng J Med 2006; 354(10): 1031-8.

[26] Colman S, Joyce T, Kaestner R. Misclassification bias and the estimated effect of parental involvement laws on adolescents' reproductive outcomes. Am J Pub Health 2008; 98(10): 1881-5.

[27] Medoff MH. The response of abortion demand to changes in abortion costs. Soc Ind Res 2008; 87(2): 329-46.

[28] Haas-Wilson D. The impact of state abortion restrictions on minors' demand for abortions. J Hum Res 1996; 31(1): 140-58.

[29] Ohsfeldt RL, Gohmann SF. Do parental involvement laws reduce adolescent abortion rates? Contemp Econ Polit 1994; 12(2): 65-76.

[30] Henshaw SK, Kost K. Parental involvement in minors' abortion decisions. Fam Plann Perspect 1992; 24(5): 196-207.

[31] Joyce T. The supply-side economics of abortion. N Engl J Med 2011; 365(16):1466-9.

[32] Medoff MH. Biased abortion counseling laws and abortion demand. Soc Sci J 2009; 46(4): 632-43.

[33] Althaus FA, Henshaw SK. The effects of mandatory delay laws on abortion patients and providers. Fam Plann Perspect 1994; 26(5): 228-31.

[34] Joyce T, Henshaw SK, Skatrud JD. The impact of Mississippi's mandatory delay law on abortions and births. J Am Med Assoc 1997; 278(8): 653-8.

[35] Joyce T, Kaestner R. The impact of Mississippi's mandatory delay law on the timing of abortions. Fam Plann Perspect 2000; 32(1): 413 .

[36] Medoff MH. A pooled time-series analysis of abortion demand. Popul Res Polit Rev 1997; 16(4): 597-605.

[37] Medoff MH Dennis C. A critical reexamination of the effect of antiabortion legislation in the post-Casey era. St Polit Policy Q 2013; Forthcoming.

[38] Jones RK, Zolna MR, Henshaw SK, Finer LB. Abortion in the United States: incidence and access to services. 2005. Perspect Sex Reprod Health 2008; 40(1): 6-16.

[39] Colman S, Joyce T. Regulating abortion impact on patients and providers in Texas. J Polit Anal Manage 2011; 30(4): 775-97.

[40] Jones BS, Weitz TA. Legal barriers to second-trimester abortion provision and public health consequences. Am J Public Health 2009; 99(4): 623-30.

[41] Brown RW, Jewell RT, Rous JJ. Provider availability, race and abortion demand. South Econ J 2001; 67(63): 656-71.

[42] Jewell RT, Brown RW. An economic analysis of abortion: the effect of travel cost on teenagers. Soc Sci J 2000; 37(1): 113-24.

[43] New MJ. Analyzing the effects of state legislation on the incidence of abortion during the 1990s. The Heritage Found 2004; Center for Data Analysis \#04-01, 2004.

[44] Gius MP. The impact of availability and legal restrictions on the demand for abortions by young women. Soc Sci J 2007; 44(3): 495-506.

[45] Medoff MH. The relationship between state abortion policies and abortion providers. Gend Issues 2009; 26(3/4): 224-37.

(C) Marshall H. Medoff; Licensee Bentham Open.

This is an open access article licensed under the terms of the Creative Commons Attribution Non-Commercial License (http://creativecommons.org/licenses/ by-nc/3.0/) which permits unrestricted, non-commercial use, distribution and reproduction in any medium, provided the work is properly cited. 